\title{
Sobre algumas espécies do gênero Eustala (Araneae, Araneidae) do Brasil
}

\author{
Maria Rita M. Poeta, Maria Aparecida L. Marques \& Erica Helena Buckup
}

Museu de Ciências Naturais, Fundação Zoobotânica do Rio Grande do Sul, Rua Dr. Salvador França, 1427, 90690-000 Porto Alegre, RS, Brasil. (maria.poeta@acad.pucrs.br; maria-marques@fzb.rs.gov.br; erica@fzb.rs.gov.br)

\begin{abstract}
On some species of the genus Eustala (Araneae, Araneidae) from Brazil. Two species of Eustala Simon, 1895 from Rio Grande do Sul, Brazil are described: Eustala belissima sp. nov. and Eustala crista sp. nov., based on males and females. The female of Eustala itapocuensis Strand, 1916, and the males of E. nasuta Mello-Leitão, 1939, E. perfida Mello-Leitão, 1947 and E. secta Mello-Leitão, 1945 are described for the first time. New records from Brazil are listed for Eustala illicita (O. P.-Cambridge, 1889) and E. sagana (Keyserling, 1893).
\end{abstract}

KEYWORDS. Spiders, taxonomy, new species, distribution, Neotropical.

RESUMO. Duas espécies de Eustala Simon, 1895 são descritas do Rio Grande do Sul, Brasil: Eustala belissima sp. nov. e Eustala crista sp. nov., representadas por ambos os sexos. A fêmea de E. itapocuensis Strand, 1916 e os machos de E. nasuta Mello-Leitão, 1939, E. perfida Mello-Leitão, 1947 e E. secta Mello-Leitão, 1945, são descritos pela primeira vez. Novas ocorrências do Brasil são listadas para Eustala illicita (O. P.-Cambridge, 1889) e E. sagana (Keyserling, 1893).

PALAVRAS-CHAVE. Aranhas, taxonomia, novas espécies, distribuição, Neotropical.

Para o Brasil, estão registradas 19 espécies de Eustala Simon, 1895, a maioria conhecida apenas por um dos sexos (Platnick, 2010). Poeta et al. (2010) acrescentaram duas espécies ao elenco do Rio Grande do Sul, Eustala levii e E. palmares, com base em machos e fêmeas, além de descrever os machos de E. taquara (Keyserling, 1892) e E. albiventer (Keyserling, 1884).

As espécies Eustala nasuta da Guiana, E. secta da Argentina e E. perfida do Paraná, Brasil, propostas respectivamente por Mello-LeITÃo $(1939,1945,1947)$ e E. itapocuensis de Santa Catarina, Brasil, descrita por STRAND (1916), até o momento, eram conhecidas apenas por um dos sexos. Neste trabalho, complementam-se as descrições destas quatro espécies de Eustala anteriormente citadas. São descritas e ilustradas duas espécies novas, com base em ambos os sexos. Para o Brasil, ocorrências adicionais são registradas para Eustala illicita (O. P.Cambridge, 1889) e E. sagana (Keyserling, 1893).

\section{MATERIAL E MÉTODOS}

A terminologia das estruturas do epígino e do palpo segue Levi (1977). Ilustrações foram realizadas sob estereomicroscópio com câmara-clara. Medidas são expressas em milímetros. O material examinado está depositado na coleção de aranhas do Museu de Ciências Naturais, Fundação Zoobotânica do Rio Grande do Sul, Porto Alegre, Rio Grande do Sul (MCN) (E. H. Buckup, curadora).

\section{Eustala belissima sp. nov. (Figs 1, 4-9)}

Tipos. Holótipo ở, parátipo 9 , Cambará do Sul, Rio Grande do Sul, Brasil, 11-19.IV.1994, M. A. L. Marques col. (MCN 46389). Parátipos: ơ, 4 , Cambará do Sul, 11-
19.IV.1994, M. A. L. Marques col. (MCN 25409); ㅇ, 1119.IV.1994, M. A. L. Marques col. (MCN 46388).

Etimologia. O nome específico é um adjetivo alusivo ao belo aspecto da aranha.

Diagnose. O palpo dos machos de Eustala belissima, similar ao da maioria das espécies do gênero com apófise terminal longa, distingue-se pelo êmbolo com uma conspícua projeção mediana (Figs 4,5). A fêmea (Figs 6-9) separa-se das espécies similares, com epígino de base anelada, pelo escapo relativamente curto e largo e pela placa mediana com sulco mediano-longitudinal posterior, em vista ventral (Fig. 6).

Macho (holótipo). Carapaça amarela, área ocular, dos olhos médios, saliente e estreita, região cefálica com pigmento branco. Clípeo baixo, com altura de aproximadamente meio diâmetro dos olhos médios anteriores. Esterno amarelo, acinzentado junto às margens. Pernas amarelas com manchas castanhas nos fêmures e tíbias, metatarsos e tarsos castanhos; tíbias com robustas macrocerdas. Abdômen subtriangular, mais longo do que largo; dorso branco com ângulos laterais anteriores conspícuos, região anterior com faixa irregular escurecida, salpicada de preto; fólio bem demarcado a partir dos três quartos posteriores. Ventre reticulado de branco com duas manchas castanhas esmaecidas.

Medidas. Comprimento total 3,3. Carapaça comprimento 1,9, largura 1,5. Pernas, fórmula 1243. Comprimento perna I: fêmur 2,9; patela + tíbia 3,1; metatarso 2,1 ; tarso 0,8 ; comprimento total 8,9 . Patela + tíbia II 2,0; III 1,0; IV 1,5.

Fêmea (parátipo, MCN 46389). Abdômen mais largo do que longo, reticulado de branco, com faixa transversal anterior pontuada de preto, que se estende lateralmente até as fiandeiras. Coloração como a do macho, exceto carapaça com maior extensão de pigmento branco (Fig. 9). 
Medidas. Comprimento total 4,7. Carapaça comprimento 1,7, largura 1,7. Pernas, fórmula 1243. Comprimento perna I: fêmur 2,5; patela + tíbia 3,0; metatarso 1,7 ; tarso 0,7 ; comprimento total 7,9 . Patela + tíbia II 2,2; III 1,2; IV 1,8.

Variação. Machos $(\mathrm{n}=3)$ : comprimento total: 3,2-3,7; carapaça: 1,9-2,0, largura 1,5-1,6. Fêmeas $(n=5)$ : comprimento total: 4,1-5,4; carapaça: 1,7-2,0, largura 1,52,0. No abdômen, o fólio pode estar reduzido ou ausente. (Fig. 1).

Distribuição geográfica. Brasil (Rio Grande do Sul)

Material examinado. BRASIL, Rio Grande do Sul: Bom Jesus, 2 \&, 01.IV.1988, A. B. Bonaldo col. (MCN 17401); (Fazenda Aver), o', ᄋ, 24.III.1989, A. B. Bonaldo col. (MCN 18421); Vacaria, , 23.V.1981, A. A. Lise col. (MCN 17822); Estrela Velha, + , 06.V.1998, A. L. H. Silva col. (MCN 29376); Caxias do Sul (Vila Oliva), + , 04.IV.1975, A. A. Lise col. (MCN 2549).

\section{Eustala crista sp. nov.}

(Figs 1, 10-15

Tipos. Holótipo ơ , parátipo $\odot$, Iraí, Rio Grande do Sul, Brasil, 18.XI.1975, A. A. Lise col. (MCN 3060, 3058, respectivamente). Parátipos: ${ }^{7}$, Estrela Velha, Rio Grande do Sul, 21.X.1998, A. B. Bonaldo col. (MCN 29546); ㅇ, 20.X.1998, A. B. Bonaldo col. (MCN 29570); 2 đ', 27.X.1998, A. B. Bonaldo col. (MCN 31505); , Maquiné, Rio Grande do Sul, 08.IV.1995, L. Moura col. (MCN 26542).

Etimologia. O substantivo específico refere-se à conspícua projeção tegular do palpo.

Diagnose. O macho de Eustala crista é semelhante aos das demais espécies do gênero que apresentam apófises terminal e subterminal reduzidas, no entanto, separa-se pela proeminente projeção tegular e forma do condutor (Figs 10, 11). A fêmea (Figs 12-15) apresenta epígino similar ao de E. latebricola (O. P.-Cambridge, 1889) e E. perfida pelo escapo curto com ápice arredondado, em vista ventral (vide CHICKERING, 1955, figs 78-80; LEVI, 2007), distingue-se dessas espécies pelo escapo distintamente largo e anelado, em vista lateral (Fig. 14).

Macho (holótipo). Carapaça amarelo-escura, laterais manchadas de castanho; região cefálica estreita levemente projetada. Esterno amarelo com manchas cinza nas margens. Pernas amarelas com bandas castanhas. Abdômen oval com ângulos anteriores quase inconspícuos, dorso com fólio e margem anterior castanho-escura. Ventre cinza com mancha mediana branca.

Medidas. Comprimento total 5,2. Carapaça comprimento 2,7, largura 2,4. Pernas, fórmula 1243. Comprimento perna I: fêmur 4,7; patela + tíbia 5,2; metatarso 3,1; tarso 1,2; comprimento total 14,2. Patela + tíbia II 3,4; III 1,7; IV 3,0.

Fêmea (parátipo, MCN 3058). Coloração semelhante a do macho, exceto carapaça com pigmento branco. Dorso do abdômen com fólio em escudo; ângulos laterais obtusos (Fig. 15).

Medidas. Comprimento total 5,9. Carapaça comprimento 2,1, largura 1,9. Pernas, fórmula 1243. Comprimento perna I: fêmur 4,2; patela + tíbia 4,5; metatarso 2,5; tarso 1,0; comprimento total 12,2. Patela + tíbia II 3,5; III 1,5; IV 2,7.

Nota. Machos e fêmeas foram colecionados juntos em quatro localidades.

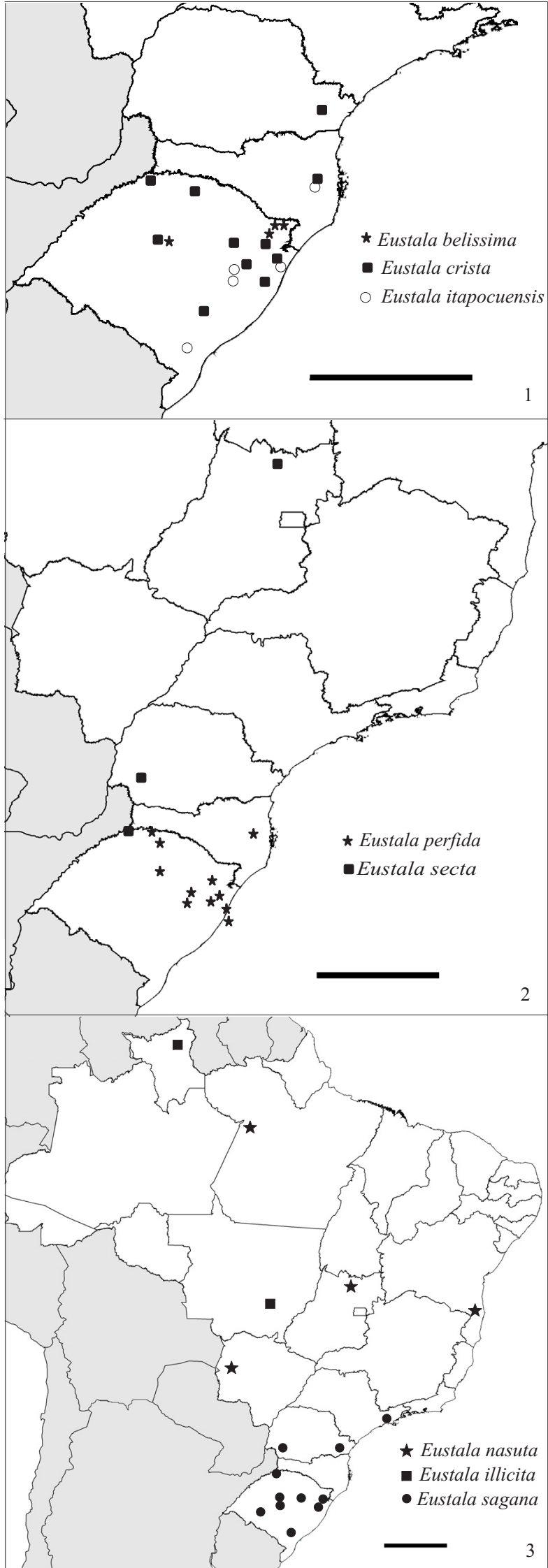

Figuras 1-3. Distribuição geográfica das espécies de Eustala. Escalas: $500 \mathrm{~km}$. 

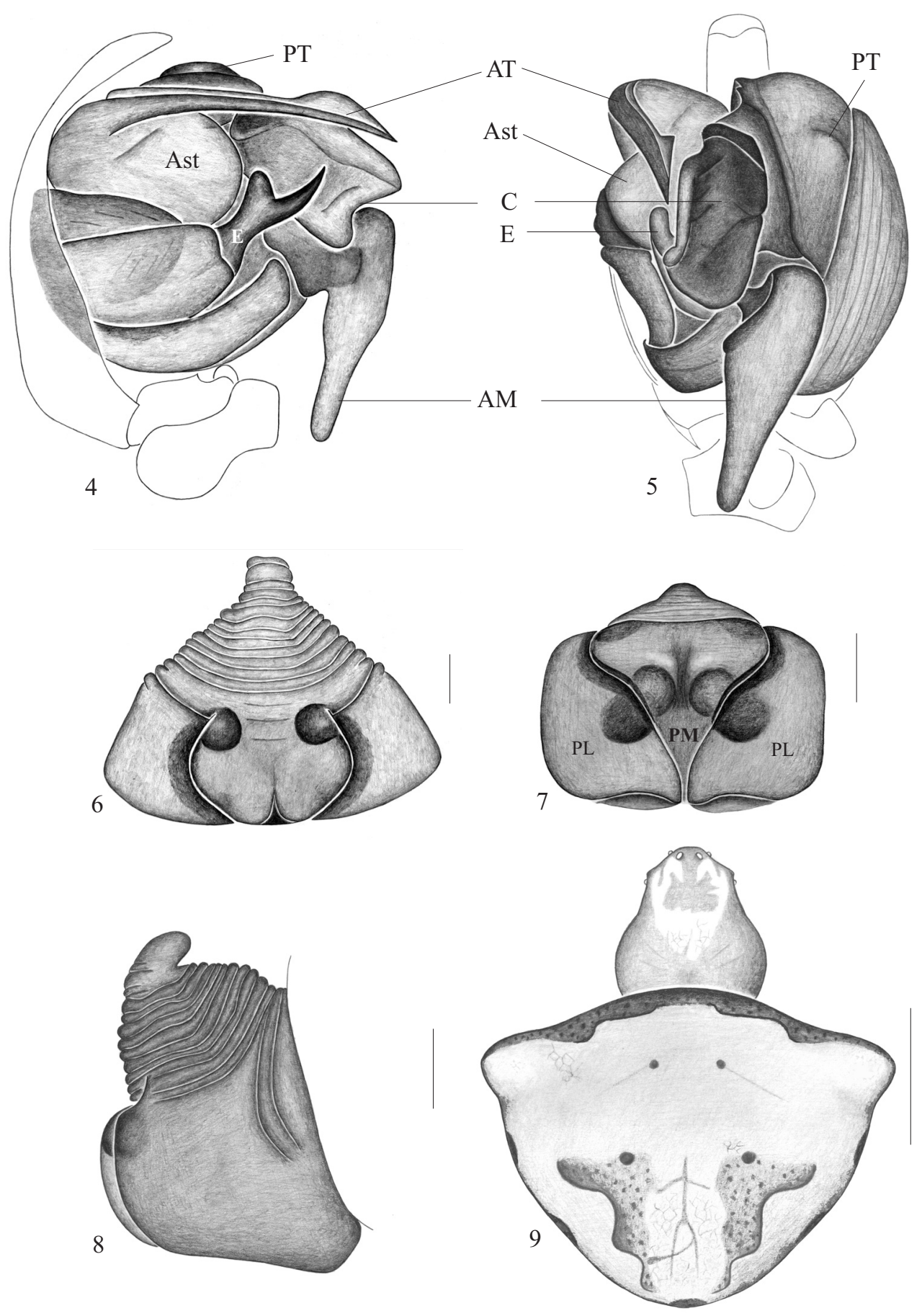

Figuras 4-9. Eustala belissima sp. nov. Palpo: 4, mesial; 5, ventral; epígino: 6, ventral; 7, posterior; 8, lateral; 9, corpo da fêmea (AM, apófise média; ASt, apófise subterminal; AT, apófise terminal; C, condutor; E, êmbolo; PL, placa lateral; PM, placa mediana; PT, projeção tegular). Escalas: Figs 4-8, 0,1 mm; Fig. 9, 1,5 mm.

Variação. Machos (n=5): comprimento total: 5,0-5,5; carapaça: $2,7-2,8$, largura 2,3-2,5. Fêmeas $(n=5)$ : comprimento total: 4,8-5,9; carapaça: 2,0-2,4, largura 1,82,0. Fólio com maior ou menor quantidade de pigmento. Em vista lateral, o ápice do escapo pode ser mais triangular.

Distribuição geográfica. Brasil (Paraná, Santa Catarina, Rio Grande do Sul) (Fig. 1).

Material examinado. BRASIL, Paraná: Almirante Tamandaré, \&, 28.X.1984, E. C. Costa col. (MCN 12515); Santa
Catarina: Rancho Queimado, +, 13-15.I.1995, L. Moura col. (MCN 26332); + , 15-18.XI.1995, A. B. Bonaldo col. (MCN 26774); Rio Grande do Sul: Derrubadas (Parque Estadual do Turvo), on, 28-31.X.2003, R. Ott col. (MCN 37577); ○’, , 19-22.X.2004, R. Ott col. (MCN 38608, 38615); São Valentim, ơ, 16.X.1976, S. Scherer col. (MCN 4702); Estrela Velha, 2 O', 20, 21.X.1998, A. B. Bonaldo col. (MCN 29546, 29571); O', 2 \%, 27, 28.X.1999, A. B. Bonaldo col. (MCN 31506, 31507, 31525); Encantado, ot, 24.V.1986, A. D. Brescovit col. (MCN 15126); Canela, + , 20.X.1997, E. H. Buckup col. (MCN 28898); o’, ९, 23-25.X.1998, L. Moura col. (MCN 29859, 29862); São Francisco de Paula, O’, ᄋ, 04.XI.1998, A. H. Silva col. (MCN 29699, 29700); Montenegro, 
, 12.VIII.2002, V. Wolf et al. col. (MCN 37130); Campo Bom, ㅇ, 19, 20.V.1986, C. J. Becker col. (MCN 15079); Porto Alegre, o, 04.IX.1977, A. A. Lise col. (MCN 6464); Viamão (Morro do Côco), ơ, 04.VIII.1975, A. A. Lise col. (MCN 3946); Maquiné, $q$, 08.IV.1995, L. Moura col. (MCN 26542); Cristal (Mata ciliar do rio Camaquã), + , 14.XI.2007, E. N. L. Rodrigues col. (MCN 46412).

\section{Eustala itapocuensis Strand, 1916}

$$
\text { (Figs 1, 16-21) }
$$

Eustala itapocuensis STRAnd, 1916:107, holótipo ơ', Joinville, Santa Catarina, Brasil (Forschunginstitut und Naturmuseum
Senckenberg, SMF). Examinado por H. W. Levi em 1976 (vide Levi, 2007); Roewer, 1942:765; Bonnet, 1956:1840; Platnick, 2010.

Diagnose. Eustala itapocuensis é similar a $E$. nasuta pela região cefálica estreita e área dos olhos médios anteriores projetada, em vista dorsal (Fig. 21; vide LEVI, 2007). O macho distingue-se pelo palpo com apófise terminal e subterminal menores, comparativamente, a Eustala nasuta, e pela forma do condutor (Figs 16, 17). A
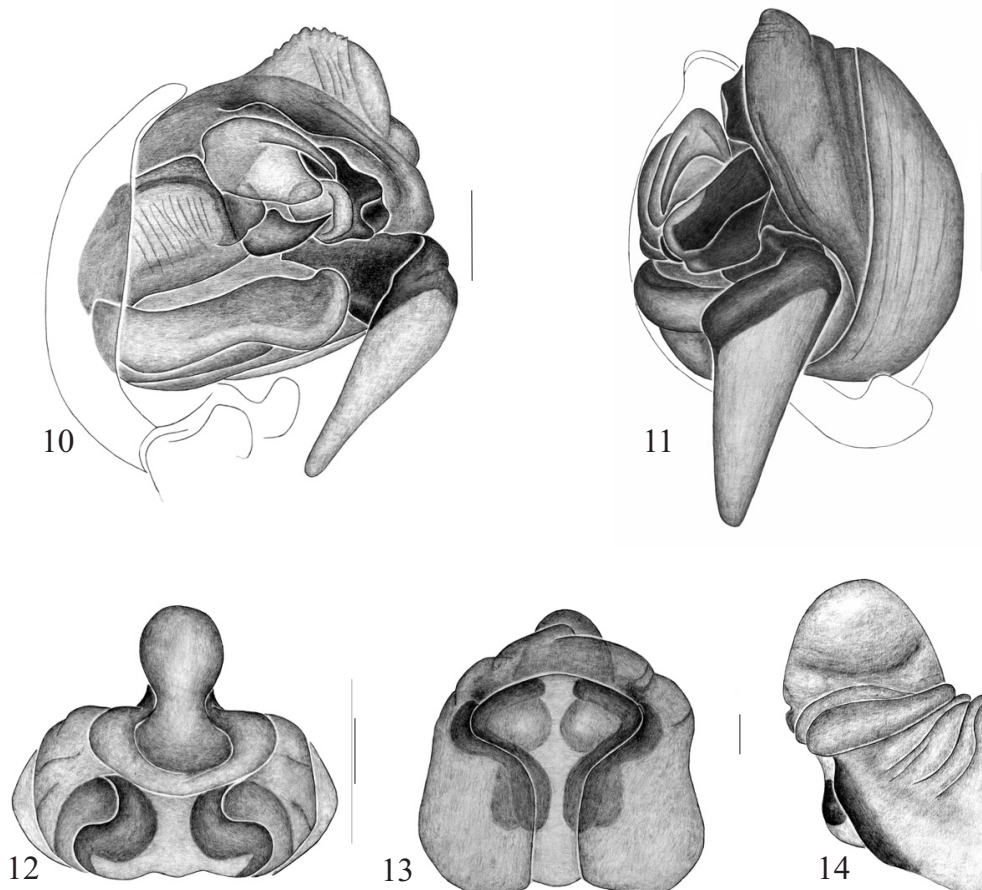

13
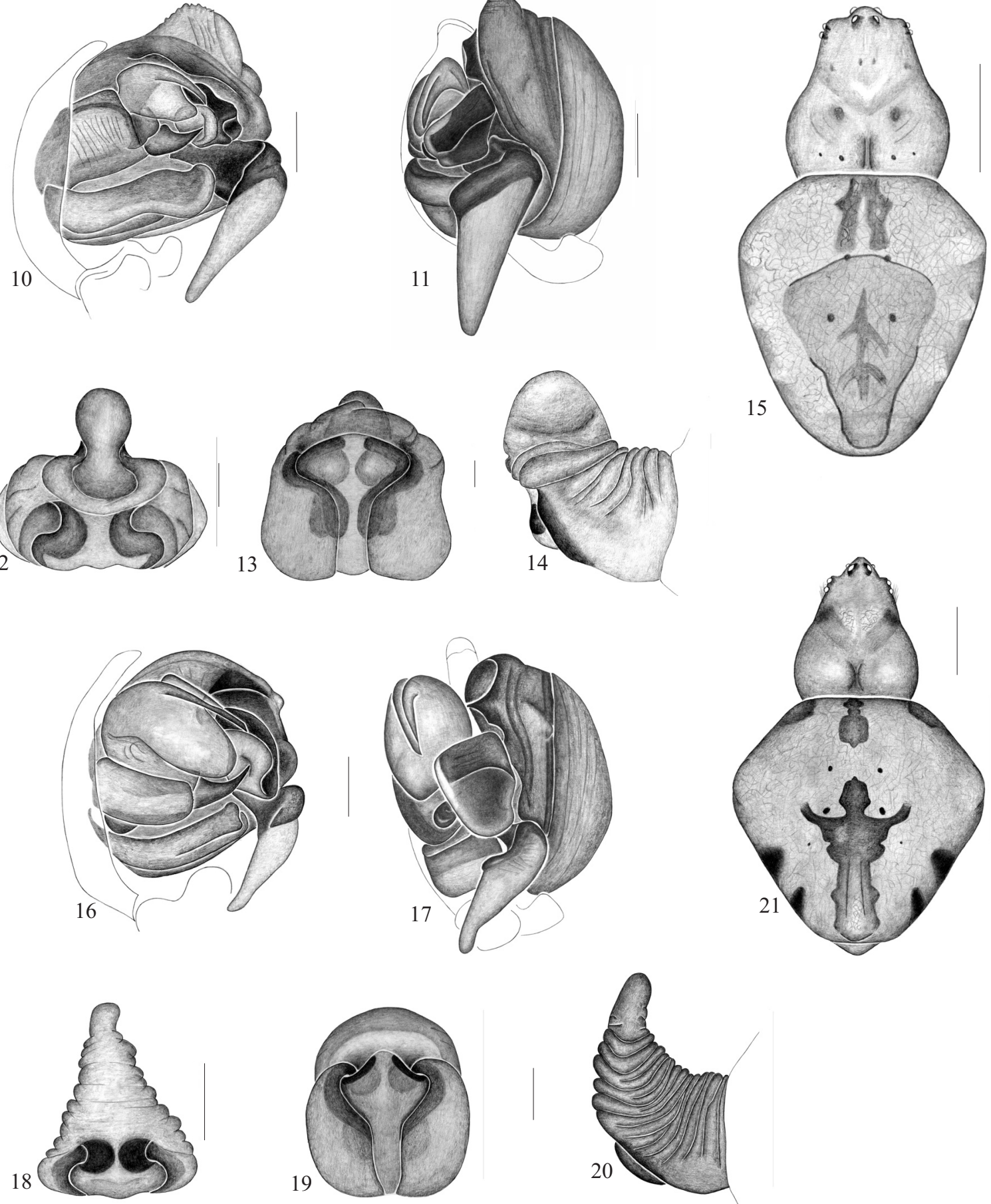

Figuras 10-21. Eustala crista sp. nov. Palpo: 10, mesial; 11, ventral; epígino: 12, ventral; 13, posterior; 14, lateral; 15, corpo da fêmea. Eustala itapocuensis Strand, 1916. Palpo: 16, mesial; 17, ventral; epígino: 18, ventral; 19, posterior; 20, lateral; 21, corpo da fêmea. Escalas: Figs 10, 11, 0,25 mm; Figs 12-14, 16-20, 0,1 mm; Figs 15, 21, 1,5 mm. 
fêmea (Figs 18-20) separa-se das demais pelo escapo anelado, piramidal, com ápice largo e curto em vista ventral (Fig. 18) e, em vista posterior, pela margem anterior da placa mediana elevada no centro (Fig. 19).

Macho (Triunfo, Rio Grande do Sul, MCN 44005). Carapaça com região cefálica estreita, levemente projetada entre os olhos medianos, amarelo-clara, com pigmento branco central; região torácica com quatro pontuações pretas. Esterno amarelo com pigmento branco anterior. Pernas amarelas, bandadas de castanho. Abdômen oval, dorso com fólio e margens escurecidas. Ventre acinzentado com manchas laterais escuras, pigmento branco próximo às fiandeiras e mancha mediana branca quase indistinta.

Medidas. Comprimento total 5,5. Carapaça comprimento 2,7, largura 2,2. Pernas, fórmula 1243. Comprimento perna I: fêmur 3,5; patela + tíbia 4,5; metatarso 3,2; tarso 1,1; comprimento total 12,3. Patela + tíbia II 3,2; III 1,6; IV 2,9.

Fêmea (Maquiné, Rio Grande do Sul, MCN 26543). Projeção cefálica como a do macho. Abdômen subtriangular, mais longo do que largo, com ângulos laterais salientes e pequeno tubérculo apical posterior. Colorido como o do macho, exceto pela ausência de pigmento branco na carapaça (Fig. 21).

Medidas. Comprimento total 7,3. Carapaça comprimento 2,6, largura 2,0. Pernas, fórmula 1243. Comprimento perna I: fêmur 3,1; patela + tíbia 3,9; metatarso 2,5; tarso 1,1; comprimento total 10,6. Patela + tíbia II 3,0; III 1,6; IV 2,4.

Nota. A associação de machos e fêmeas, colecionados em Capão do Leão, foi efetuada com base na forma da região cefálica, estreita e projetada entre os olhos médios anteriores (Fig. 21) e tamanho corporal.

Variação. Machos ( $n=3)$ : comprimento total: 5,4-5,5; carapaça: 2,7-3,1, largura 2,2-2,4. Fêmeas $(n=5)$ : comprimento total: 5,2-7,3; carapaça: 2,4-2,6, largura 1,82,0 . O pigmento branco pode ou não estar presente na carapaça e no esterno.

Distribuição geográfica. Brasil (Santa Catarina, Rio Grande do Sul) (Fig. 1).

Material examinado. BRASIL, Santa Catarina: Rancho Queimado, +, 15-18.XI.1995, A. B. Bonaldo col. (MCN 26771); Rio Grande do Sul: Eldorado do Sul (Parque Estadual Delta do Jacuí), 4 ㅇ, 05-07.I.2000, A. B. Bonaldo col. (MCN 31807); Triunfo, , 15.IX.1977, E. H. Buckup col. (MCN 6582); (Parque Copesul de Proteção Ambiental), ơ, 14.II.2008, R. Moraes col. (MCN 44005); Maquiné, ㅇ, 08.IV.1995, L. Moura col. (MCN 26543); Barra do Ribeiro (Fazenda Boa Vista), ㅇ, 12.V.2003, Equipe Probio col. (MCN 35577); Capão do Leão (Horto Botânico Irmão Teodoro Luís, em ninhos de vespas), 2 ơ, 2 ㅇ, 25.V.2001, E. N. L. Rodrigues col. (MCN 46397).

\section{Eustala perfida Mello-Leitão, 1947} (Figs 2, 22-26)

Eustala perfida Mello-Leitão, 1947:243, fig. 11, holótipo 9 , Volta Grande, Paraná, Brasil, B. Hertel col. (depositado no Museu Paranaense, atualmente Museu de História Natural Capão da Imbuia, Curitiba, $\mathrm{n}^{\circ}$ 2495). Holótipo examinado por H. W. Levi em 1988 (vide Levi, 2007); Brignoli, 1983:270; Platnick, 2010.

Diagnose. O palpo do macho de Eustala perfida é similar ao de E. crista (Figs 10,11) pela apófise subterminal reduzida, distingue-se pela apófise terminal mais longa, pelas duas pequenas projeções tegulares, em vista ventral, e pela forma do condutor (Figs 22, 23). A fêmea assemelha-se a E. crista pelo escapo curto e arredondado, em vista ventral (Fig. 12), mas distingue-se desta pela placa mediana ampla, mais longa do que larga, em vista ventral (Fig. 24); em vista posterior, placas laterais gradativamente convergentes (Fig. 25) e, em vista lateral, bordas das placas laterais espessas e bem-demarcadas (Fig. 26).

Macho (Triunfo, RS, MCN 36072). Carapaça amarela, região torácica com faixas laterais castanhas. Olhos médios posteriores rodeados por losango preto. Esterno amarelo-escuro com pigmento branco mediano. Pernas amarelas com manchas anelares castanhas. Abdômen oval, mais longo do que largo; dorso com ângulos laterais e ápice posterior inconspícuos, fólio com uma faixa mediano-longitudinal castanho-escura. Ventre castanho com pontuações brancas e mancha branca mediana.

Medidas. Comprimento total 5,7. Carapaça comprimento 3,3, largura 2,5. Pernas, fórmula 1423. Comprimento perna I: fêmur 3,2; patela + tíbia 4,0; metatarso 2,7; tarso 1,2, comprimento total 11,1. Patela + tíbia II 3,1; III 1,9; IV 3,4.

Fêmea (Triunfo, RS, MCN 36072). Carapaça amarela com faixas torácicas castanhas mais curtas e estreitas que as do macho. Abdômen subtriangular, margens laterais com três tubérculos pouco distintos e ápice posterior inconspícuo. Demais aspectos semelhantes aos do macho.

Medidas. Comprimento total 7,1. Carapaça comprimento 2,9, largura 2,2. Pernas, fórmula 1243. Comprimento perna I: fêmur 3,0; patela + tíbia 3,7; metatarso 2,2; tarso 0,9; comprimento total 9,8. Patela + tíbia II 3,3; III 1,7; IV 3,0.

Nota. Espécimes de ambos os sexos foram colecionados juntos em três localidades e compartilham o mesmo padrão de colorido.

Variação. Machos (n=5): comprimento total: 5,3-6,4; carapaça: 2,9-3,3, largura 2,3-2,6. Fêmeas $(n=5)$ : comprimento total: 6,6-7,1; carapaça: 2,7-3,2, largura 1,72,5. Região cefálica pode apresentar área branca. Faixas escuras nas laterais da carapaça das fêmeas algumas vezes ausentes. Esterno com maior ou menor quantidade de pigmento branco. O fólio pode estar desbotado. As pregas do epígino podem ser mais ou menos distintas, em vista ventral.

Distribuição. Brasil (Paraná, Santa Catarina, Rio Grande do Sul) (Fig. 2).

Material examinado. BRASIL, Santa Catarina: Rancho Queimado, 3 o', 08-11.X.1994 (MCN 26176, 26179); 2 क, 1518.XI.1995 (MCN 26772, 26773), todos coletados por A. B. Bonaldo \& L. Moura; Rio Grande do Sul: Iraí, +, 19.XI.1975, A. A. Lise col. (MCN 3141); São Valentim, + , 16.X.1976, S. Scherer col. (MCN 4660); Passo Fundo, o, 12.X.1985, A. A. Lise col. (MCN 14343); Bom Jesus, + , 28-31.III.1998, A. B. Bonaldo col. (MCN 29283); Cambará do Sul (Área de Preservação Ambiental Celulose Cambará), 2 ㅇ, 19-21.XII.1994, M. H. Galileo col. (MCN 25960); Caxias do Sul, , 04.X.1994, L. Moura col. (MCN 25905); (Vila Oliva), 4 , 15.I.1974, F. R. Meyer col. (MCN 274); Canela, ơ, , 26.XII.1976, A. A. Lise col. (MCN 3712); Montenegro, 2 , 07.VIII.1977, A. A. Lise col. (MCN 6122); Triunfo (Parque Copesul de Proteção Ambiental), O', 2 + , 05.II.2003, R. Ott col. (MCN 35131, 35189, 35190); ㅇ, 29, 30.IV.2003, R. Ott col. (MCN 35717); o', 4 +, 29.VII.2003, R. Ott \& A. Barcellos col. (MCN 
36072); 3 O', 4 ค, 21.X.2003, R. Ott \& L. Podgaiski col. (MCN 36444); O 25.I.1995, A. Franceschini col. (MCN 26488); Eldorado do Sul (Parque Estadual Delta do Jacuí), 2 ơ, 8 \&, 05-07.I.2000, A. B. Bonaldo col. (MCN 31808); Viamão, , 11-14.IV.1983, A. A. Lise col. (MCN 11550); O’, 08.II.1999, E. N. L. Rodrigues col. (MCN 37428); (Parque Saint Hilaire), ơ, 22.VII.1974, A. A. Lise col. (MCN 2355).

\section{Eustala secta Mello-Leitão, 1945 (Figs 2, 27-31)}

Eustala secta Mello-leitão, 1945:238, fig. 11, holótipo P, Puerto Victoria, Misiones, Argentina, Zenzes col. (Museo La Plata, ${ }^{\circ}$
16390). Examinado por H. W. Levi em 1974 (vide Levi, 2007); Brignoli, 1983:270; Podgaiski et al., 2007:6; Platnick, 2010.

Diagnose. Machos de Eustala secta distinguemse dos das demais espécies pelo palpo bem-diferenciado, com a apófise subterminal posicionada acima da apófise terminal; uma projeção tegular muito desenvolvida, próxima ao ápice do címbio, outra no lado oposto, bifurcada apicalmente e com prolongamento posterior; êmbolo com uma lamela linguiforme; condutor laminar membranáceo (Figs 27, 28). Fêmeas (Figs 29-31) separam-
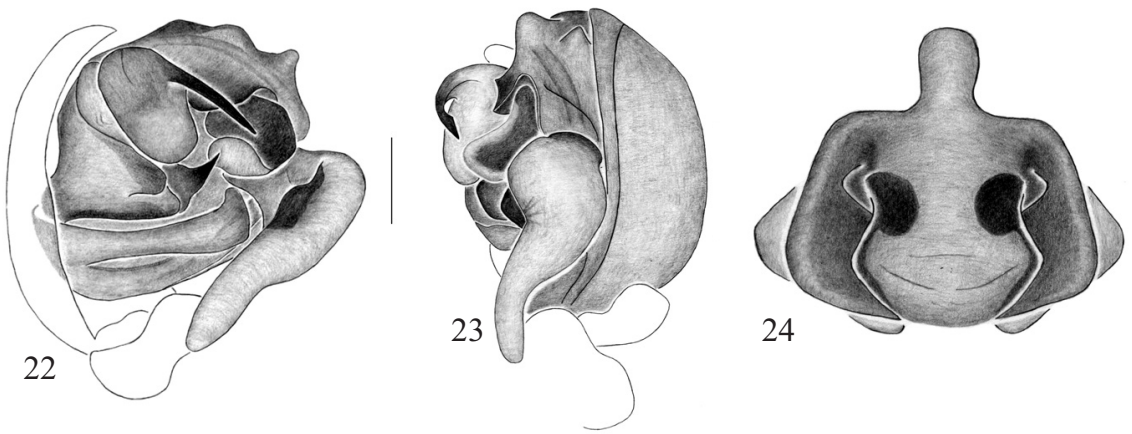

25
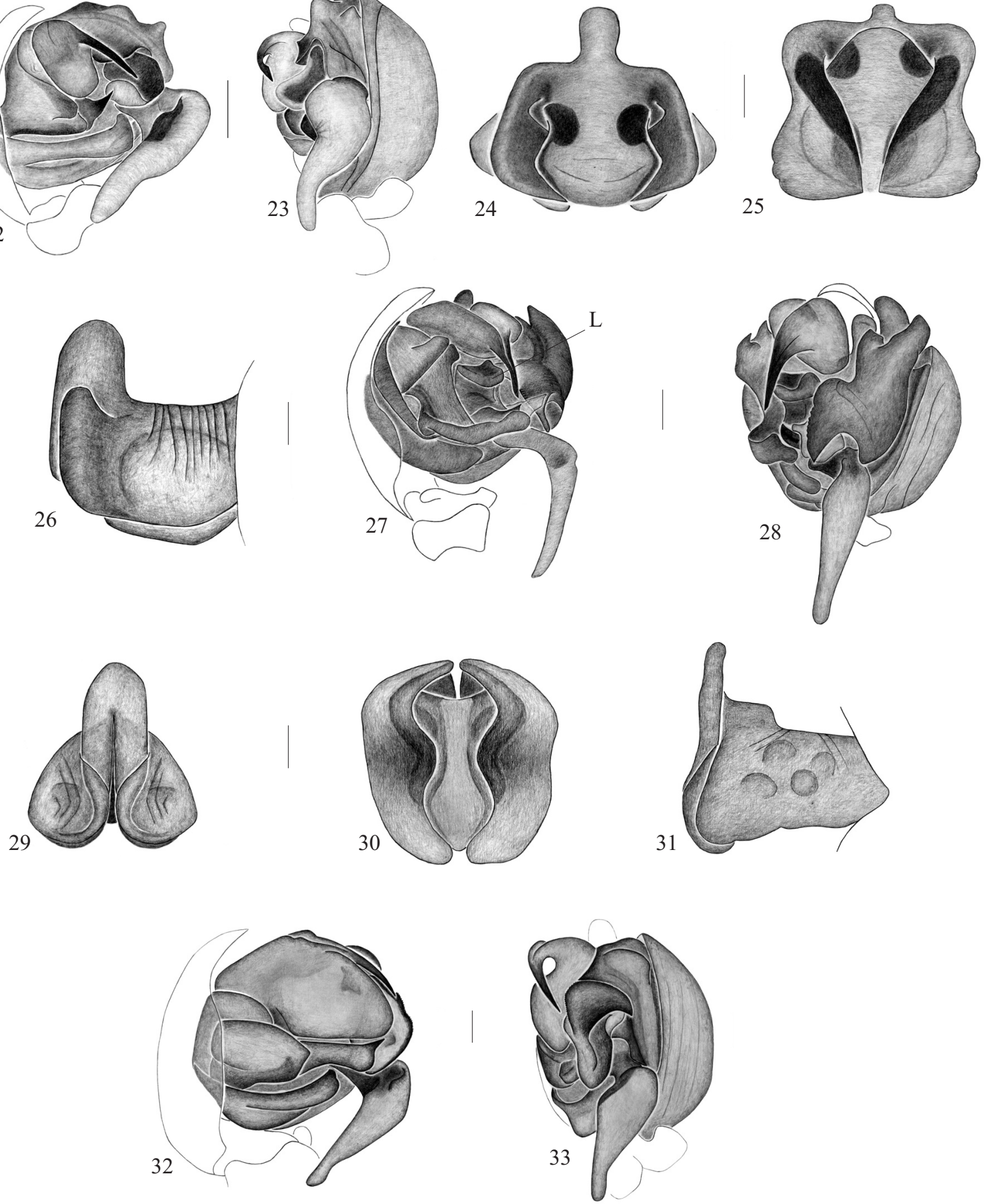

Figuras 22-33. Eustala perfida Mello-Leitão, 1947. Palpo: 22, mesial; 23, ventral; epígino: 24, ventral; 25, posterior; 26, lateral. Eustala secta Mello-Leitão, 1945. Palpo: 27, mesial; 28, ventral; epígino: 29, ventral; 30, posterior; 31, lateral. Eustala nasuta Mello-Leitão, 1939. Palpo: 32, mesial; 33, ventral (L, Lamela do êmbolo). Escalas: Figs 22, 23, 0,25 mm; Figs 24-33, 0,1 mm. 
se pela forma do epígino que, em vista ventral, apresenta escapo largo com fissura mediano-longitudinal e base alargada com bordas arredondadas (Fig. 29), em vista lateral, escapo muito estreito (Fig. 31).

Macho (Derrubadas, Rio Grande do Sul, MCN 37578). Carapaça amarelo-clara, com manchas castanhas. Esterno amarelo-claro com margem acinzentada. Pernas amarelas com manchas anelares castanho-claras. Abdômen oval, mais longo do que largo; dorso com fólio, ápice posterior indistinto. Ventre amarelo-claro com vestígio de pigmento branco na região mediana.

Medidas. Comprimento total 3,7. Carapaça comprimento 2,4, largura 1,6. Pernas, fórmula 1243. Comprimento perna I: fêmur 3,1; patela + tíbia 3,4; metatarso 2,3; tarso 0,8; comprimento total 9,6. Patela + tíbia II 2,3; III 1, 1 ; IV 2,0.

Fêmea (Derrubadas, Rio Grande do Sul, MCN 38593). Carapaça amarela manchada de castanho. Esterno amarelo-claro, com margens escurecidas. Pernas amareloclaras com bandas castanhas. Abdômen subtriangular, dorso com margem anterior escurecida, com fólio. Ventre cinza com mancha branca mediana.

Medidas. Comprimento total 2,8. Carapaça comprimento 1,9, largura 1,6. Pernas, fórmula 1243. Comprimento perna I: fêmur 2,8; patela + tíbia 3,0; metatarso 2,0; tarso 0,8; comprimento total 8,6. Patela + tíbia II 2,2; III 1,2; IV 2,0.

Nota. Levi (1977) observou que, pelo epígino peculiar, esta espécie poderia se tratar de uma Metazygia, o que só poderia ser confirmado com a presença do macho. A fêmea tem todas as características somáticas de Eustala. Machos e fêmeas de Eustala secta, colecionados juntos em duas localidades, foram associados pelo tamanho, forma e aspecto corporal.

Variação. Machos (n=2): comprimento total: 3,3-3,7; carapaça: 1,7-2,4, largura 1,4-1,6. Fêmeas $(n=5)$ : comprimento total: 3,9-4,7; carapaça: 1,7-2,0, largura 1,41,7. A carapaça pode ou não apresentar manchas escuras. O padrão de colorido do dorso do abdômen varia, podendo ser mais ou menos pigmentado; alguns exemplares têm o fólio pouco aparente e as faixas pretas e brancas anteriores podem estar ausentes. O ápice do epígino pode ser pontudo ou mais arredondado.

Distribuição. Brasil (Goiás, Paraná, Rio Grande do Sul); Argentina (Misiones) (Fig. 2).

Material examinado. BRASIL, Goiás: Minaçu (Usina Hidrelétrica Serra da Mesa), + , 18-30.XI.1996, A. B. Bonaldo \& L. Moura col. (MCN 28104); Paraná: Três Barras do Paraná, ơ ,, , 20-26.II.1993, A. B. Bonaldo col. (MCN 22998); Rio Grande do Sul: Derrubadas (Parque Estadual do Turvo), o, 29.XI.1978, H. Bichoff col. (MCN 8442); , 11.IX.1976, S. Scherer col. (MCN 4621); 6 , 19-22.X.2003, R. Ott et al. col. (MCN 38593, 46996); o, o, 28-31.X.2003, R. Ott et al. col. (MCN 37578, 37613).

\section{Eustala nasuta Mello-Leitão, 1939}

(Figs 3, 32, 33)

Eustala nasuta Mello-Leitão, 1939:107, figs 5, 6, holótipo 9 , Guiana, O. W. Richards col. Examinado por H. W. Levi em 1973, depositado no The Natural History Museum, Londres (vide LEVI, 2007). Roewer, 1942:766; Bonnet, 1956:1841; Platnick, 2010.

Diagnose. O macho de E. nasuta separa-se de espécies similares com área ocular projetada (LEVI, 2007), pelo êmbolo longo com lóbulo basal e ápice curto e pela forma diferenciada do condutor, em vistas mesial e ventral (Figs 32, 33). A fêmea de E. nasuta distingue-se pela região ocular elevada e projetada e pela localização dos olhos médios nesta projeção; epígino com escapo anelado e placa mediana com um entalhe posterior, em vista ventral (vide LEVI, 2007).

Macho (Minaçu, Goiás, MCN 28017). Carapaça amarela-escura, com cerdas esparsas, região cefálica estreitando-se gradualmente, área entre os olhos médios projetada anteriormente. Olhos médios anteriores muito afastados da borda do clípeo e olhos médios posteriores circundados por losangos pretos. Esterno amarelo com retículo branco anterior. Pernas amarelas, com manchas escuras pouco definidas. Abdômen oval, dorso com fólio e tubérculos marginais, inconspícuos, um tubérculo mediano abaixo do ápice posterior. Ventre escuro com mancha branca, esmaecida.

Medidas. Comprimento total 5,5. Carapaça comprimento 2,7, largura 2,0. Pernas, fórmula 1243. Comprimento perna I: fêmur 3,5; patela + tíbia 4,8; metatarso 2,5 ; tarso 0,8 ; comprimento total 11,6. Patela + tíbia II 3,5; III 1,8; IV 3,2.

Fêmea (Santarém, Pará, MCN 25336). Aranha com área cefálica distintamente projetada, semelhante a do macho. Abdômen com três tubérculos posteriores (vide LEVI, 2007). Dorso branco com bordas pretas, mancha anterior longitudinal e mediana preta. Ventre com mancha branca mediana, grande e arredondada.

Medidas. Comprimento total 8,7. Carapaça comprimento 3,2, largura 3,0. Pernas, fórmula 1243. Comprimento perna I: fêmur 3,5; patela + tíbia 5,7; metatarso 2,9; tarso 1,0; comprimento total 13,1. Patela + tíbia II 5,3; III 2,5; IV 4,7.

Nota. Macho e fêmeas foram associados pela forma da região cefálica, muito projetada anteriormente, onde estão inseridos os olhos médios, distantes da borda do clípeo. Olhos laterais próximos a margem do clípeo.

Variação. Fêmeas (n=3): comprimento total: 6,6-8,7; carapaça: 3,0-3,2, largura 2,2-3,0. A carapaça pode ou não apresentar pigmento branco, em "V", na região cefálica. Um exemplar apresenta o abdômen subtriangular.

Distribuição. Guiana; Brasil (Pará, Goiás, Bahia, Mato Grosso do Sul) (Fig. 3).

Material examinado. BRASIL, Pará: Santarém, , 28.I.1994, A. D. Brescovit col. (MCN 25336); Goiás: Minaçu (Usina Hidroelétrica Serra da Mesa), ơ', 09-20.XII.1996, A. Franceschini col. (MCN 28017); Bahia: Camacan (Fazenda Matiapã), $q$, 14.X.1978, J. S. Santos col. (MCN 11079); Mato Grosso do Sul: Pantanal (30 km de Miranda), 9 , 30.VII.1982, A. Langguth col. (MCN 25769).

\section{Eustala illicita (O. P.-Cambridge, 1889)}

(Fig. 3)

Epeira illicita O. P.-CAmbridge, 1889:17, tipo + , est. 6, fig. 16, Yzabal, Guatemala, Sarg col.

Epeira cambridgii KeYsERLING, 1893:255, est. 13, fig. 190, síntipos , Guatemala. Sinonimizada por F. O. P.-CAMBrIDGE, 1904:506. Larinia illicita; SIMON, 1895:795.

Eustala illicita; F. O. P.-CAmBridge, 1904:506, est. 48, fig. 5, O’’ fig. 6, 9 , Atoyac, México e Guatemala, depositados na coleção 
Godman \& Savin. Examinados por H. W. Levi em 1975, no The Natural History Museum (Levi, 2007). Petrunkevitch, 1911:342;

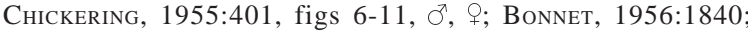
Platnick, 2010.

Diagnose. Eustala illicita assemelha-se às espécies do grupo E. fuscovitatta pelo abdômen alongado. Machos distinguem-se pelo êmbolo conspícuo e distinta forma das apófises terminal e subterminal (vide Levi, 2007). Fêmeas diferem das demais espécies do grupo pela forma característica do escapo, semelhante a um losango, em vista ventral (vide LEVI, 2007).

Distribuição. México (Atoyac); Guatemala (Yzabal); Brasil (Roraima, Mato Grosso) (Fig. 3).

Material examinado. BRASIL, Roraima: Alto Alegre, Ilha de Maracá, + , 17.VII.1987, A. A. Lise col. (MCN 27494); Mato Grosso: Chapada dos Guimarães, + , 18.XI.1983, M. Hoffmann col. (MCN 11981).

\section{Eustala sagana (Keyserling, 1893) (Fig. 3)}

Epeira sagana Keyserling, 1893:254, est. 13, fig. 189, síntipos o e + , Rio de Janeiro, Brasil, E. Göldi col. Examinados por H. W. Levi em 1976, no The Natural History Museum (Levi, 2007). Araneus saganus; Petrunkevitch, 1911:314; Bonnet, 1956:589. Eustala sagana; Roewer, 1942:766; Platnick, 2010.

Diagnose. Machos de Eustala sagana distinguemse dos das demais espécies, que apresentam o abdômen alongado, pelo condutor com prolongamento posterior estreito. Fêmea separa-se pelo escapo sem projeção basal, em vista lateral, e pela placa mediana posteriormente demarcada por uma depressão circular (vide LEVI, 2007; KEYSERLING, 1893)

Distribuição. Brasil (Rio de Janeiro, São Paulo, Paraná e Rio Grande do Sul) (Fig. 3).

Material examinado. BRASIL, São Paulo: Ubatuba (Praia Domingas Dias), O', 14.II.1988, A. B. Bonaldo col. (MCN 17336); Paraná: Três Barras do Paraná, $q$, 20-26.II.1993, A. B. Bonaldo col. (MCN 22995); Morretes, +, 28, 29.X.1993, A. B. Bonaldo col. (MCN 26722); Rio Grande do Sul: Derrubadas (Parque Estadual do Turvo), +, 27.X.2002-01.XI.2002 (MCN 38713); 6 , 28-31.X.2003 (MCN 37541, 38106); ㅇ, 19-22.X.2004 (MCN 38605), todos coletados por R. Ott; Tenente Portela, , 11.IX.1976, S. Scherer col. (MCN 4565); Júlio de Castilhos, 2 9, 22.X.1998, L. Moura col. (MCN 30603); Estrela Velha, ㅇ, 20.X.1998, A. B. Bonaldo col. (MCN 29573); + , 07.III.2001, R. Ott col. (MCN 33677); ㅇ, 30.X.2001, A. Franceschini col. (MCN 34109); Pinhal Grande, , 07.V.1998, M. A. L. Marques col. (MCN 29379); Farroupilha,, , 25.II.2003, J. E. F. Dorneles col. (MCN 37518); São Francisco de Paula, , 04.XI.1998, A. B. Bonaldo col. (MCN 29703); Candelária (Cerro do Botucaraí), +, 05-09.II.2001, A. Franceschini col. (MCN 33608); , 08, 09.X.2001, A. Franceschini col. (MCN 34068); Morro Reuter, ㅇ, 07.X.1967, A. A. Lise col. (MCN 531); Pelotas,, , 08.VIII.2003, E. N. L. Rodrigues col. (MCN 37426).
Agradecimentos. À Diretora Executiva do MCN, Maria de Lourdes Abruzzi A. de Oliveira pela disponibilização de equipamentos. Ao CNPq pela bolsa de Iniciação Científica (PIBIC - processo $n^{\circ}$ 105695/2009-2) à primeira autora.

\section{REFERÊNCIAS BIBLIOGRÁFICAS}

Bonnet, P. 1956. Bibliographia Araneorum. Toulouse, Douladoure. v.2, pt.2, p.919-1926.

Brignoli, P. M. 1983. A catalogue of the Araneae described between 1950 and 1981. Manchester, Manchester University. $755 \mathrm{p}$.

Cambridge, O. P.- 1889. Arachnida-Araneidea. In: Biologia Centrali-Americana, Zoology. London. v.1, pt.1, p.1150 .

Cambridge, F. O. P.- 1904. Arachnida-Araneidea and Opiliones. In: Biologia Centrali-Americana, Zoology. London. v.2, pt.3, p.425-610.

Chickering, A. M. 1955. The genus Eustala in Central America. Bulletin of the Museum of Comparative Zoology 112:391-518.

Keyserling, E. 1893. Die Spinnen Amerikas. Nürenberg, Bauer \& Raspe. v.4, pt.2, p.209-377.

Levi, H. W. 1977. American orb-weaver genera Cyclosa, Metazygia and Eustala north of Mexico (Araneae, Araneidae). Bulletin of the Museum of Comparative Zoology 148(3):61-127.

2007. Type species of araneid and tetragnathid genera. Harvard University. Disponível em: <http:// www.oeb.harvard.edu/faculty/levi>. Acesso em: 10.01.2010.

Mello-Leitão, C. F. 1939. Some new Argiopid spiders of British Guiana taken by Mr. C. W. Richards from the nests of solitary wasps. Annaes da Academia Brasileira de Sciencias 11(2): 105-112.

. 1945. Arañas de Misiones, Corrientes y Entre Ríos. Revista del Museo de La Plata, Nueva Série, Zoología 4(29):213302 .

1947. Aranhas do Paraná e Santa Catarina, das coleções do Museu Paranaense. Arquivos do Museu Paranaense 6(6):231-304.

Petrunkevitch, A. 1911. A synonymic index-catalogue of spiders of North, Central and South America with all adjacent islands, Greenland, Bermuda, West Indies, Terra del Fuego, Galapagos, etc. Bulletin of the American Museum of Natural History 29:1-791.

Platnick, N. I. 2010. The world spider catalog, version 10.5 American Museum of Natural History. Disponível em: <http:/ /research.amnh.org/entomology/spiders/catalog/index.html>. Acesso em: 19.04.2010.

Podgaiski, L. R.; Ott, R.; Rodrigues, E. N. L.; Buckup, E. H. \& Marques, M. A. L. 2007. Araneofauna (Arachnida; Araneae) do Parque Estadual do Turvo, Rio Grande do Sul, Brasil. Biota Neotropica 7(2):1-15.

Poeta, M. R. M.; Marques, M. A. L. \& Buckup, E. H. 2010. O gênero Eustala (Araneae, Araneidae) no sul do Brasil: duas espécies novas, descrições complementares e novas ocorrências. Iheringia, Série Zoologia, 100(2):151-161.

Roewer, C. F. 1942. Katalog der Araneae von 1758 bis 1940 Bremen, Natura. Bd.1, 1040p.

Simon, E. 1895. Histoire Naturalle des Araignées. Paris, Librairie Encyclopédique de Roret. 10. ed., v.1, pt.4, p.7611084 .

Strand, E. 1916. Systematische-faunistische studien über paläarktische, afrikanische und amerikanische Spinnen des Senckenbergischen Museums. Archiv für Naturgeschichte 81(9): $1-153$. 